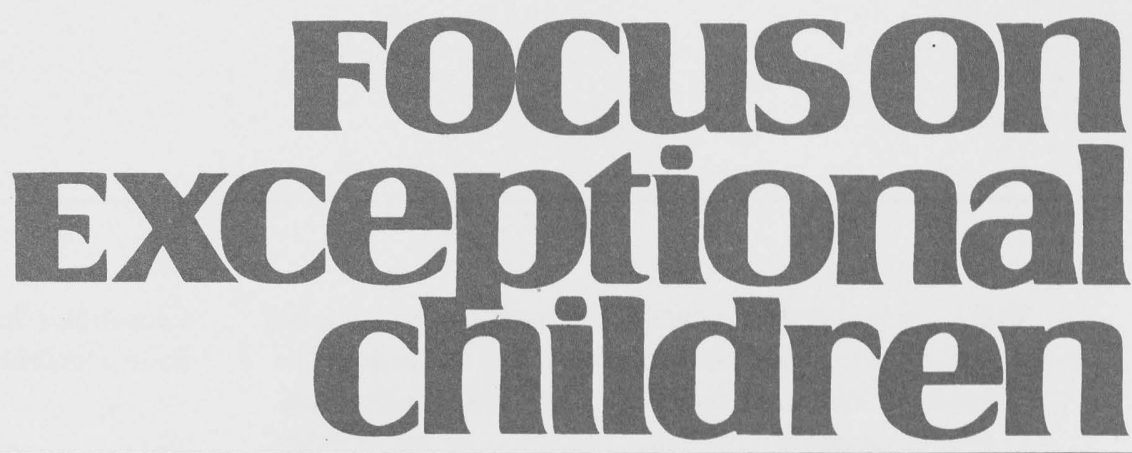

\title{
Assistive Technology and Students with Mild Disabilities
}

\author{
Dave L. Edyburn
}

The use of technology in special education technology has evolved considerably in the 1990s. Therefore, it is somewhat surprising that literature searches using the descriptors "assistive technology" and "mild disabilities" yield few articles (Behrmann, 1994; Bryant, Bryant, \& Raskind, 1998, Raskind, Higgins, Slaff, \& Shaw, 1998), book chapters (Okolo, 2000), and conference papers (Edyburn, 1996), given the prevalance of assistive technology and the fact that mild disabilities are high-incidence. Despite the explosion of products and developments in the marketplace, the profession to date, has been slow to recognize the need to integrate state-of-the-art technology into special education programs and services for students with mild disabilities.

One possible explanation for the limited attention to assistive technology and mild disabilities is that the area is still in its infancy. This perspective can be supported from a historical viewpoint as well as a policy perspective. Historically, assistive technology devices and services have been associated with individuals who have physical and sensory impairments and moderate or severe needs.

As special educators were introduced to assistive technology in the forms of alternative keyboards, switches, and Braille printers, it is understandable that the application of these tools for students with mild disabilities were not readily apparent. New language in the Individuals with Disabilities Education Act (IDEA) Amendments of 1997 (Public Law 105-17) however, now requires that assistive technology be considered when planning the individualized education program (IEP) of all students with disabilities. Thus, the 1997 reauthorization of IDEA serves as a marker event defining a new era relative to mild disabilities and assistive technology.

The purpose of this article is to provide an in-depth review of research, policy, and practice relative to the use of assistive technology by students with mild disabilities. It is organized into four sections.

1. Given the multidisciplinary nature of assistive technology assessment, we'll begin with a brief overview of the common characteristics of mild disabilities and then examine the potential of technology for individuals with disabilities, with specific attention to assistive technology.

2. Because IEP teams must document their efforts to consider assistive technology for each student, we'll examine the requirement for considering assistive technology along with resources that facilitate the process.

Dave Edyburn is with the Department of Exceptional Education, University of Wisconsin-Milwaukee. 
3. We'll advance four new directions that offer promise for capturing the potential of assistive technology for students with mild disabilities: (a) recognize the contributions and limitations of technology for enhancing performance, (b) reconceptualize the forms of assistive technology, (c) redesign assistive technology service delivery systems, and (d) respond to the need to document the impact and effectiveness of assistive technology.

4. Even though the challenges confronting the profession concerning assistive technology and mild disabilities are significant, the current state of affairs also provides opportunities. We'll conclude by outlining the implications of this work for research, policy, and practice.

\section{KEY CONCEPTS}

As a background for the discussion, this article just provides an overview of common characteristics associated with mild disabilities, the potential of technology for individuals with disabilities, and an introduction to assistive technology.

\section{Focuson
Exceptional children}

ISSN 0015-511X FOCUS ON EXCEPTIONAL CHILDREN (USPS 203-360) is published monthly except June, July, and August as a service to teachers, special educators, curriculum specialists, administrators, and those concerned with the special education of exceptional children. This publication is annotated and indexed by the ERIC Clearinghouse on Handicapped and Gifted children for publication in the monthly Current Index to Journals in Education (CIJE) and the quarterly index, Exceptional Children Education Resources (ECER). The full text of Focus on Exceptional Children is also available in the electronic versions of the Education Index. It is also available in microfilm from Xerox University Microfilms, Ann Arbor, MI. Subscription rates: Individual, \$30 per year; institutions, $\$ 40$ per year. Copyright (C) 2000, Love Publishing Company. All rights reserved. Reproduction in whole or part without written permission is prohibited. Printed in the United States of America. Periodicals postage is paid at Denver, Colorado. POSTMASTER: Send address changes to:

\section{Love Publishing Company \\ Executive and Editorial Office P.O. Box 22353 \\ Denver, Colorado 80222 \\ Telephone (303) 221-7333}

$\begin{array}{cc}\begin{array}{c}\text { Karen Harris } \\ \text { University of Maryland }\end{array} & \begin{array}{c}\text { Thomas Skrtic } \\ \text { University of Kansas }\end{array} \\ \text { James Shriner } & \text { Stanley F. Love } \\ \text { University of Illinois } & \text { Publisher }\end{array}$

\section{Common Characteristics Associated with Mild Disabilities}

Typically, mild disabilities are classified as learning disabilities, emotional/behavioral disorders, and mental retardation. These disabilities are defined as follows in the IDEA '97 Final Regulations ( $\$ 300.7$ Child with a disability):

\section{Learning Disabilities}

(10) Specific learning disability is defined as follows: (i) General. The term means a disorder in one or more of the basic psychological processes involved in understanding or in using language, spoken or written, that may manifest itself in an imperfect ability to listen, think, speak, read, write, spell, or to do mathematical calculations, including conditions such as perceptual disabilities, brain injury, minimal brain dysfunction, dyslexia, and developmental aphasia. (ii) Disorders not included. The term does not include learning problems that are primarily the result of visual, hearing, or motor disabilities, of mental retardation, of emotional disturbance, or of environmental, cultural, or economic disadvantage. (Authority: 20 U.S.C. 1401(3)(A) and (B); 1401(26))

\section{Emotional/Behavioral Disorders}

(4) Emotional disturbance is defined as follows: (i) The term means a condition exhibiting one or more of the following characteristics over a long period of time and to a marked degree that adversely affects a child's educational performance: (A) An inability to learn that cannot be explained by intellectual, sensory, or health factors. (B) An inability to build or maintain satisfactory interpersonal relationships with peers and teachers. (C) Inappropriate types of behavior or feelings under normal circumstances. (D) A general pervasive mood of unhappiness or depression. (E) A tendency to develop physical symptoms or fears associated with personal or school problems. (ii) The term includes schizophrenia. The term does not apply to children who are socially maladjusted, unless it is determined that they have an emotional disturbance. (Authority: 20 U.S.C. 1401(3)(A) and (B); 1401(26))

\section{Mental Retardation}

(6) Mental retardation means significantly subaverage general intellectual functioning, existing concurrently with deficits in adaptive behavior and manifested during the developmental period, that adversely affects a child's educational performance. (Authority: 20 U.S.C. 1401(3)(A) and (B); 1401(26))

To summarize the characteristics often associated with mild disabilities, Meese (2001) describes the following: cognitive characteristics (intellectual ability, attentional deficits, memory and thinking skills); academic characteristics (reading, language arts, mathematics) and social-emotional characteristics (pp. 27-35). Students with mild disabilities typically receive special education services in the general education classroom, resource room, or a self-contained special education classroom. 
As has been the case historically, recent data from the U.S. Department of Education (2000), indicate that the majority of students receiving special education services, $71 \%$, have mild disabilities (LD, ED/BD, MR). As we turn our attention to technology, we must keep in mind that we are talking about the assistive technology needs of more than 3.8 million students, ages 6-21, with mild disabilities.

\section{Potential of Technology for Individuals with Disabilities}

Left undefined, the term technology often is unfortunately considered synonomous with computers. Blackhurst (1997) has suggested that four different forms of technology are relevant to special education and rehabilitation: the technology of teaching, medical technology, instructional technology, and assistive technology.

1. The technology of teaching involves the pedagogy that we utilize in designing instruction and learning environments for individuals with disabilities.

2. Medical technology refers to new experimental treatments, prostheses, wheelchairs, lifts, and the like.

3. Instructional technology covers software and hardware specifically designed to enhance teaching and learning.

4. Assistive technology consists of devices and services that enhance the performance of individuals with a disability by enabling them to complete tasks more effectively, efficiently, and independently than otherwise possible.

Although all four defintions are relevant to the field of special education technology, given the contexts of schooling and mild disabilities, this review will focus broadly on the technology of teaching, instructional technology, and assistive technology.

The fields of special education and rehabilitation have had a longstanding interest in technology and the potential it holds for individuals with disabilities (Blackhurst, 1997; Blackhurst \& Edyburn, 2000; Fein, 1996; Hannaford, 1993.) One of the first public-policy documents to draw attention to the potential of technology was Technology and Handicapped People (U.S. Congress, Office of Technology Assessment, 1982). This report introduced readers to specialized technology tools, how they serve specific individuals, and the impact of the devices on their lives.

These real-life stories serve as powerful illustrations of the potential of technology for individuals with disabilities. Indeed, as a result of these early success stories, and others that would be collected and shared in subsequent years, the argument was advanced that public investment in research and development in the area of technology and disability could reap significant dividends in the form of improved communication skills, expanded mobility and independence, and an increase in the number of individuals gainfully employed and contributing to the tax base. The argument delineating the benefits of technology for individuals with disabilities was so persuasive that it led to the enactment of federal laws to provide mechanisms for capturing the potential of technology on an ever-increasing scale.

A pattern of federal legislation has emerged in which the potential of technology for individuals with disabilities has been consistently advanced. Most notably, this includes the Technology Related Assistance for Individuals Act (the Tech Act), passed in 1988, and the 1997 reauthorization of the Individuals with Disabilities Education Act.

Thus, in the relatively brief span of 15 years since publication of Technology and Handicapped People (U.S. Congress, Office of Technology Assessment, 1982), Congress has been effectively persuaded by the success stories to enact a change strategy utilizing federal policy and major funding initiatives as a mechanism to foster the rapid expansion of research, development, and adoption of technology by individuals with disabilities. Therefore, the potential of technology for individuals with disabilities has been recognized and valued as an area of national investment that offers significant dividends.

\section{Assistive Technology}

Two dimensions of assistive technology are recognized in federal law (IDEA '97 Final Regulations): (a) assistive technology devices, and (b) assistive technology services. These definitions were originally developed as part of the 1988 Tech Act legislation and subsequently have been cited or incorporated into all technology and disabilitiy legislation (Americans with Disabilities Act, 1990; Individuals with Disabilities Education Act Amendments, 1997; Telecommunications Act of 1996; Assistive Technology Act of 1998). As you read the following definition of an assistive technology device, pay careful attention to its encompassing nature:

\section{$\$ 300.5$ Assistive technology device.}

As used in this part, Assistive technology device means any item, piece of equipment, or product system, whether acquired commercially off the shelf, modified, or customized, that is used to increase, maintain, or improve the functional capabilities of a child with a disability. (Authority: 20 U.S.C. 1401(1))

Although many people believe the term assistive technology applies only to computers, in reality, assistive technology devices (e.g., adaptive feeding instruments, wheelchairs, vision aids) have a long history in the field of special education and rehabilitation. Current estimates suggest that more than 25,000 assistive technology devices have been designed to enhance the life functioning of individuals with 
disabilities (Able Data, 2000). Nonetheless, some have argued that the definition is so broad that it could include anything; others have noted that the definition simply reflects the fact that assistive technology solutions may involve no technology, low technology, or high technology. In the subsequent section on consideration, we'll revisit these concepts as they apply to mild disabilities.

The second definition advances a critical component involved in the effective use of assistive technology: Success depends not only on having access to a device but also factors involving selection, acquisition, and use of a tool. These ideas are codified in the following definition of assistive technology services:

\begin{abstract}
\$300.6 Assistive technology service.
As used in this part, Assistive technology service means any service that directly assists a child with a disability in the selection, acquisition, or use of an assistive technology device. The term includes (a) The evaluation of the needs of a child with a disability, including a functional evaluation of the child in the child's customary environment; (b) Purchasing, leasing, or otherwise providing for the acquisition of assistive technology devices by children with disabilities; (c) Selecting, designing, fitting, customizing, adapting, applying, maintaining, repairing, or replacing assistive technology devices; (d) Coordinating and using other therapies, interventions, or services with assistive technology devices, such as those associated with existing education and rehabilitation plans and programs; (e) Training or technical assistance for a child with a disability or, if appropriate, that child's family; and (f) Training or technical assistance for professionals (including individuals providing education or rehabilitation services), employers, or other individuals who provide services to, employ, or are otherwise substantially involved in the major life functions of that child. (Authority: 20 U.S.C. 1401(2))
\end{abstract}

The definitions of assistive technology devices and assistive technology services provide a comprehensive perspective on processes that enable individuals with disabilities to acquire and use assistive technologies that enhance functional capabilities.

\section{HAS ASSISTIVE TECHNOLOGY BEEN CONSIDERED?}

As described earlier, two factors that contributed to passage of the federal laws centered on the apparent value of technology already available in the marketplace for individuals with disabilities and that an exceedingly small number of people were currently benefiting from existing technology. In the view of Congress, two specific acts have created opportunities for systematic access to technology by individuals with disabilities.

1. The 1988 Tech Act funded the creation of State-based systems for delivering assistive technology services and devices.
2. The Individuals with Disabilities Education Act Amendments of 1997 specifically requires IEP teams to consider assistive technology when planning the educational programs of students with disabilities.

In this section we will examine the process of "considering assistive technology" and offer a critique of the current state of affairs. Then we'll comment briefly on the challenges and opportunities that lie ahead concerning assistive technology and mild disabilities.

\section{Issues Involved in Consideration}

The issue of assistive technology consideration is a rather recent development. Its origin can be traced to the Individuals with Disabilities Education Act Amendments of 1997 (Public Law 105-17), which contained a requirement for individualized education program (IEP) teams to consider assistive technology in the development of an IEP: "The IEP Team shall . . . consider whether the child requires assistive technology devices and services" [Section 614 (d)(3)(B) Consideration of Special Factors].

Although some observers believe this language reflects a new federal policy, Golden (1998) argues that it simply formalizes a previous responsibility:

The IDEA requires schools to provide AT if it is needed for a student to receive a free appropriate publication education (FAPE). FAPE can include a variety of services such as special education, related services, supplementary aids and services, program modifications or support for school personnel. AT, just like other components of FAPE, must be provided at no cost to parents. The specific IDEA requirement for schools to provide AT is as follows:

\subsection{Assistive Technology}

Each public agency shall ensure that assistive technology devices or assistive technology services or both, as those terms are defined in 300.5-300.6 are made available to a child with a disability if required as part of a child's (a) Special education under 300.17; (b) Related services under 300.16; or (c) Supplementary aids and services under 300.550(b)(2)." (p. 4)

Golden's analysis highlights a critical issue: free appropriate public education (FAPE). Schools are required to provide assistive technology for students who need such tools, if they are necessary, for the student's participation in and benefit from a free appropriate public education. The historical implications of this requirement are unquestioned in the context of mobility (e.g., a powered wheelchair) and communication (e.g., an augmentative communication system). The requirement, however, covers all disabilities, and, therefore, issues such as the following have emerged: Jimmy's handwriting is not legible; therefore, he needs a laptop computer. Though such a claim and solution may be certified by an IEP team, the budgetary implications of this mandate, 
when applied to a high-incidence population, have created an environment in which administrators are reluctant to approve requests for assistive technology for students with mild disabilities given the fact that they have 50 students like Jimmy within their building. Of course, interventions other than a laptop computer also may be appropriate.

Given the recency of the requirement to "consider assistive technology," there has been a tremendous need in the field for training and resources. Several noteworthy resources have been developed to assure that the intent of the legislation does in fact get implemented by including students, parents, teachers, administrators, and technology specialists in the consideration process.

The SETT Framework, created by Joy Zabala (2000), focuses the attention of IEP teams on the student, the environment, the tasks required for active participation in the activities of the environment, and then the tools needed for the student to address the tasks. SETT was designed to facilitate gathering and organizing data to enhance assistive technology decision-making (see Table 1). This model has been widely adopted and implemented because of the intuitive nature of the four core areas, its ease of use in assessment and decision-making, and the fact that the student is the initial and primary focus. In addition, this model illustrates how changes in the environment, or the task, can fundamentally alter the need for tools-which is the final consideration.

As school districts seek to implement assistive technology on a systemic basic, an analysis by Golden (1999) can be used to sensitize administrators to the gap between students currently using assistive technology and the potential number who could benefit (see Table 2). To arrive at an estimate of the size of the population of students receiving special education that could potentially benefit from assistive technology, she developed conservative projections of the number of students who should be using assistive technology using the diagnostic categories in Missouri. The estimates were based on the typical types of educational needs students have in academic areas, study skills, daily living, leisure/recreation, and program accessibility and insight concerning the types of assistive technology that are available to address such needs.

The purpose of this exercise is to offer some benchmarks for schools to use in a programmatic evaluation of whether they are adequately addressing assistive technology needs (e.g., if your school has a number of students with visual impairments who are not using any assistive technology, you should find out why).

Finally, Toni Chambers' book, Has Technology Been Considered? A Guide for IEP Teams (1997) is an acknowledged key resource on the topic of assistive technology consideration. She observed that the 1997 reauthorization of

\section{TABLE 1 Joy Zabala's SETT Framework}

Who and What

The Student

The Tasks

The Tools
The Environment

\section{Questions}

What does the student need to do?

What are the student's current abilities?

What are the student's special needs?

What materials and equipment are currently available in the environment where the student functions?

What is the physical arrangement? Are there special concerns?

What is the instructional context? Are there likely to be changes?

What supports are available to the student?

What resources are available to the people supporting the student?

What activities take place in the environment?

What activities support the student's curriculum?

What are the critical elements of the activities?

How might the activities be modified to accommodate the student's special needs?

How might technology support the student's active participation in those activities?

What no-tech, low-tech, and hightech options should be considered when developing a system for a student with these needs and abilities doing tasks in these environments?

What strategies might be used to invite increased student performance?

How might these tools be tried with the student in the customary environments in which they will be used?

Source: From Has Technology Been Considered? A Guide for IEP Teams by A. C. Chambers (Reston, VA: CASE/TAM Assistive Technology Policy and Practice Group, Council for Exceptional Children, 1997, pp. 27-28).

IDEA required that assistive technology be considered but that the legislation offered no guidelines on how to implement the requirement. Her book was an outcome of her 


\section{TABLE 2 \\ Projected Assistive Technology Use}

\section{Disability}

Deaf and Hard of Hearing
Blind and Visually Impaired
Physical Disability
Deaf/Blind
Multiple Disabilities
Traumatic Brain Injury
Autism
Learning Disability
Health Impairment
Cognitive Disability
Speech/Language Disorder
Emotional Disability

\section{Expected Use of AT}

$100 \%$

$100 \%$

$100 \%$

$100 \%$

$100 \%$

$50-75 \%$

$50-75 \%$

25-35\%

25-35\%

25-35\%

$10-25 \%$ *

$10-25 \%$
*Most students who need or use augmentative communication devices have an identified disability other than "speech/language," thus the lower projected use for this diagnostic category.

Source: Golden, D. (1999). Assistive technology policy and practice. What is the right thing to do? What is the reasonable thing to do? What is required and must be done? Special Education Technology Practice, 1(1), 12-14. Used with permission.

research, which involved a delphi study of assistive technology experts and focus groups with trainers and consumers of assistive technology services. A valuable component of Chambers' work is the model, illustrated in Figure 1, outlining a flowchart of questions that an IEP team should ask and answer. As a result of engaging in the process, she argues, teams will automatically generate the documentation of their assistive technology consideration efforts on behalf of a child.

\section{A Critique of the Current State of Affairs}

A limited amount of research informs our knowledge about assistive technology relative to user perspectives (Todis, 1996; Todis \& Walker, 1993), family expectations (Parette \& Hourcade, 1997; Raskind, Higgins, Slaff, \& Shaw, 1998; Wehmeyer, 1999), multicultural considerations (Parette \& Hourcade, 2000), and the state of assistive technology services in public schools (Derer, Polsgrove, \& Rieth, 1996; Hutinger, Johanson, \& Stoneburner, 1996; McGregor \& Pachuski, 1996). Indeed, significant gaps remain in what we know. For example, some questions that urgently outline what we need to know, are:

How many certified assistive technology specialists are employed full-time in public schools?

What is the composition of assistive technology teams in public schools?

What is the caseload of an AT team?
Do all students who could potentially benefit from assistive technology have access to appropriate devices and services?

How long does it take to assess the need for assistive technology, acquire devices, train, and implement?

What is the quality of assistive technology services?

What impact does the use of assistive technology have on the academic performance of its users?

While we wait for additional research regarding such critical questions, anecdotal evidence permits several observations to be made about current assistive technology practices in special education:

- It is common practice to utilize a multidisciplinary team made up of teachers, technology specialists, occupational therapist, speech therapist, and physical therapist when conducting an assistive technology evaluation.

- Most individuals participating in an assistive technology team do so as a result of part-time release from their regular case/teaching load.

- Most assistive technology evaluations involve an indepth evaluation that, in many respects, mirrors the special education referral process and, therefore, is perhaps comparable in terms of cost, time involved, and efficiency.

- Little evidence is available to suggest that schools use any systemic screening process to identify students who potentially could benefit from assistive technology.

- Students who have access to assistive technology often do so as the result of advocacy efforts that challenge the system rather than through a systemic process that ensures that all students in need of devices have them.

- Of the many students who currently use assistive technology, the most common applications involve technologies that overcome physical challenges or enhance communication abilities.

- Most AT teams lament that most of their time is spent assessing new students for assistive technology needs rather than being engaged in ongoing support and follow-up of current assistive technology-using students. Implicitly, the emphasis is on acquisition (i.e., shopping), rather than on implementation and assessment of outcomes (i.e., enhanced performance).

These realities reflect the challenges involved in the policychange strategy of observing the potential of technology, as it has been demonstrated in individual cases, and then trying to capture the potential in large-scale implementation efforts. As the kaleidoscope of issues associated with assistive 


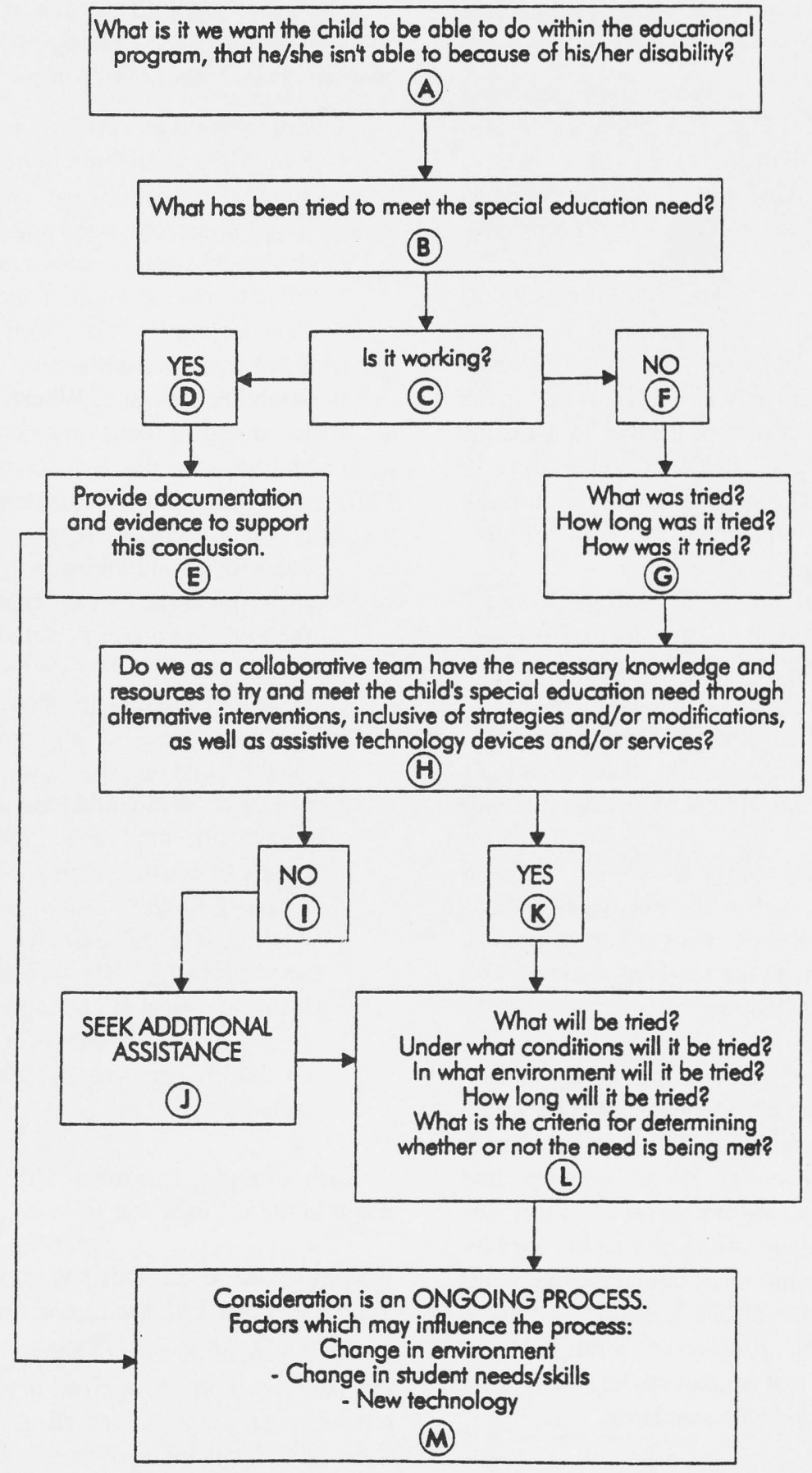

\section{FIGURE 1}

Consideration: A Flowchart of Primary Questions 
technology and mild disabilities begin to come into focus, we may recognize that:

- Currently, there is a critical shortage of personnel trained in assistive technology. The shortage is so significant that most school districts are unlikely to have even one full-time assistive technology specialist to support the needs of all students receiving special education services.

- The pipeline preparing new special education technology specialists is severely constricted. A review of personnel-preparation programs in assistive technology by RESNA identified only 21 programs across the country that provide coursework leading to a certificate or degree in special education technology. In practice, this means that individuals desiring training in assistive technology will find fewer than one program for every two states in the country.

- In the RESNA listing, no training programs were found to specifically prepare assistive technology specialists with an emphasis on mild disabilities.

- Per federal mandate, every IEP team is required to document its efforts to consider assistive technology. As it pertains to students with mild disabilities (LD, $\mathrm{ED}, \mathrm{MR}$ ), ages 6-21, this affects more than 3.8 million students.

- The current assistive technology service delivery system, developed to respond to the needs of students with low-incidence disabilities does not seem capable of being scaled-up to meet the needs of students who have high-incidence disabilities.

Thus, the current system of assistive technology assessment and service delivery does not seem adequate for meeting the demands that will be required of it as students with high-incidence disabilities need access to services and devices. As a result, there is an urgent unmet need to focus attention and resources on the use of assistive technology by students with mild disabilities to meet the legislative mandate in the 1997 reauthorization of IDEA and, more important, to ensure that state-of-the art resources, strategies, and tools are utilized in a manner that enables students with mild disabilities to achieve high academic standards.

\section{NEW DIRECTIONS IN ASSISTIVE TECHNOLOGY AND MILD DISABILITIES}

Although the challenges confronting the profession concerning mild disabilities and assistive technology are significant, the current state of affairs also provides opportunities. In contrast to the assistive technology devices and services that have been created to meet the needs of students with low-incidence disabilities, new directions could facilitate the use of assistive technology by students with mild disabilities. Four areas offer promise:

1. Recognize the contributions and limitations of technology for enhancing performance. There is often a significant gap between realistic expectations and the hype that surrounds the potential of a given technology device. Models of performance support can offer new frameworks for assistive technology consideration.

2. Reconceptualize the forms of assistive technology. What does an assistive technology device for a mild disability look like? Whereas many types of assistive technologies focus on extending physical or sensory abilities, the primary focus for students with mild disabilities must be understood to involve technologies that enhance cognitive performance and social/ behavioral functioning.

3. Redesign service delivery systems. The sheer size of the high incidence population requires a rethinking of service delivery systems such that the first step in accessing assistive technology services should not be to refer a child for a comprehensive multi-disciplinary evaluation. Designing and disseminating technology toolkits could have a profound impact for students with mild disabilities by providing routine access to assistive technology.

4. Respond to the need to document the impact and effectiveness of assistive technology. To ensure accountability, claims of technology-enhanced performance must be documented with evidence of a student's performance of a specific task during two conditions: unaided and with the use of an assistive technology device.

Each of these initiatives will be described in greater detail in the sections that follow.

\section{Recognize the Contributions and Limitations of Technology for Enhancing Performance}

The potential of technology for individuals with disabilities has been long recognized in the special education and rehabilitation communities (Blackhurst, 1997). To understand why this is the case requires insight into the relationships among the concepts of impairment, disability, handicap, and assistive technology:

An impairment [is] "any loss or abnormality of psychological, physical, or anatomical structure or function." A disability results when the impairment leads to an inability to "perform an activity in the manner or within the range considered normal for a human being (e.g., difficulties in communicating, hearing, moving about, or manipulating objects). A handicap results when the individual with an 


\begin{abstract}
impairment or disability is unable to fulfill his or her normal role. According to these definitions, a handicap is not a characteristic of a person; it is a description of the relationship between the person and the environment... This approach provides an important perspective on the role of assistive technologies in reducing the handicapping effects of disabilities. Describing persons with disabilities in this way also emphasizes functional outcomes, instead of focusing on limitations, and assistive technologies are employed primarily to contribute to successful functional outcomes for persons with disabilities. (Cook \& Hussey, 1995, p. 5), with quotes from the World Health Organization, 1980)
\end{abstract}

Thus, assistive technology offers a means for enhancing functional performance when a person with a disability is unable to perform an activity that other people normally can complete. Hence, the essence of our assistive technology efforts must center on the individual (as noted in the SETT Framework, Zabala, 2000) with the primary consideration being improved peformance:

[The] assistive technology selection system has as its emphasis using what function is available (human component) to accomplish what is desired (activity) in a given context (place, environment, people). We are not concerned as much with remediation of a disability as we are with enabling functional results and helping the individual to achieve what he or she wants to accomplish. Functional results require that we maximize the skills of the person with a disability. This places human performance at the center of our system. (Cook \& Hussey, 1995, p. 46)
Cook and Hussey point out a subtle but essential question for members of an IEP team to discuss as part of the assistive technology consideration process: When do we recognize the limitations of instructional or remediation strategies to enable an individual to achieve a specified level of performance, and when do we decide that assistive technology can be utilized to enable the individual to achieve a functional level of performance?

When attempting to design interventions that enhance human performance, conceptual models can inform our understanding of the contributions and limitations of assistive technology for individuals with disabilities. Indeed, many theorists have advanced models that attempt to describe the individual components affecting human performance in any number of tasks (Baily, 1989, Gilbert, 1978; Mager, 1992; Rossett, 1992; Spitzer, 1991).

Wile (1996) studied five common models of human performance technology and sought to reconcile the differences through a normalization process to produce a synthesis of the many dimensions that have been identified as contributing to performance. A graphic illustrating the relationships among the components of Wile's model is given in Figure 2.

Wile's analysis suggests that performance can be affected by seven variables: (1) organizational systems, (2) incentives, (3) cognitive support, (4) tools, (5) physical environment, (6) skills/knowledge, and (7) inherent ability. The

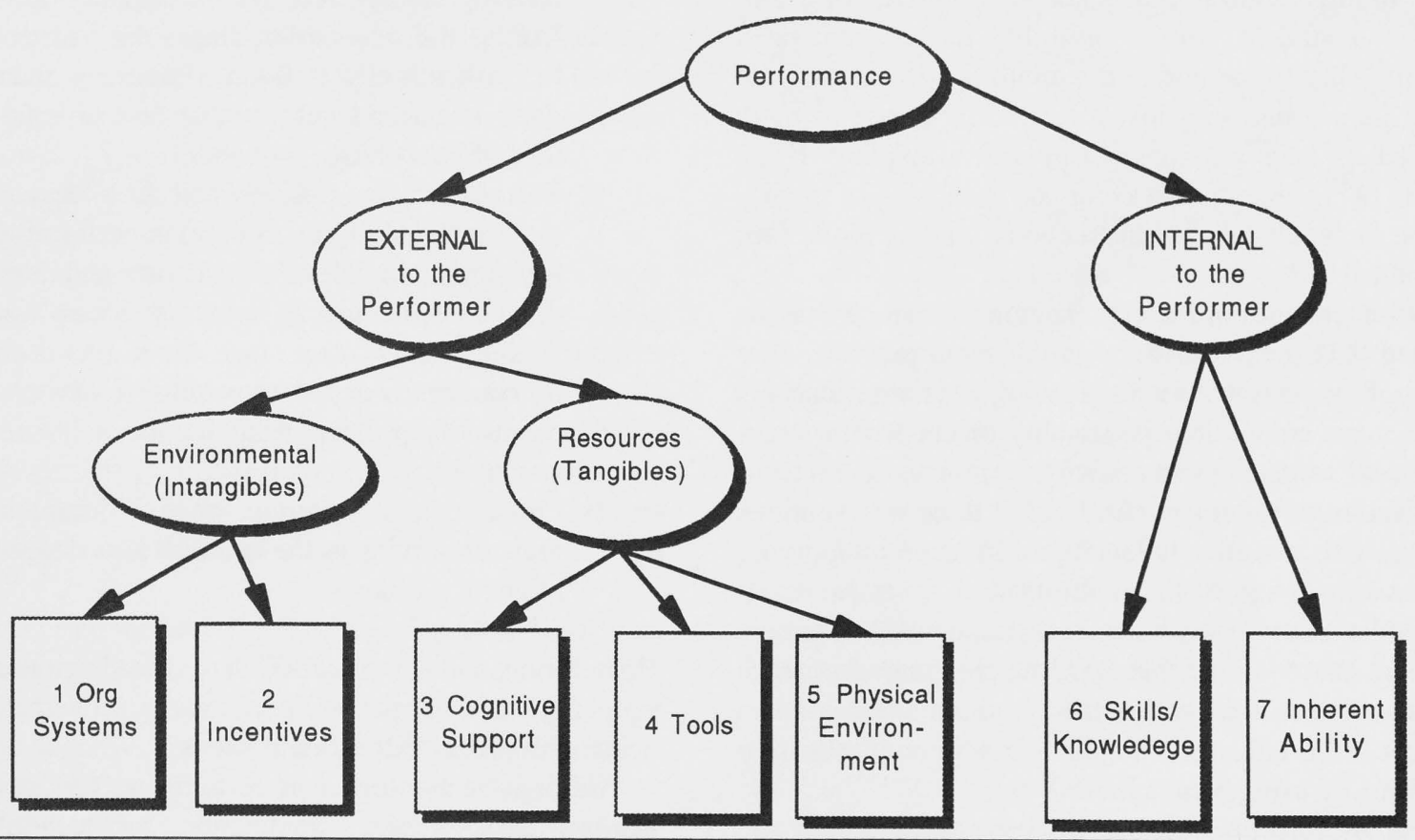

FIGURE 2

Wile's Model of Human Performance Technology 
variables can be viewed as part of two classes: those that are internal to the performer (\#6 \& \#7) and those that are external (\#1, \#2, \#3, \#4, \#5). Further, the external variables can be understood as part of environmental factors, or intangibles (\#1 \& \#2) and resources, or tangibles (\#3, \#4, \#5). Performance problems may be traced to a single variable or a combination. In Wile's estimation, the variables are sequenced in their ease of remediation. That is, problems related to organizational system variables (\#1) are easier to modify than problems associated with intrinsic abilities (\#7).

Traditionally, poor performance was considered the result of inadequate training (\#6) or a deficit within the individual (\#7) that made him or her unsuitable for the task. As the model illustrates, however, a range of factors, such as poor working conditions $(\# 1, \# 5)$ or lack of incentives (\#2) may also be valid explanations of poor performance.

This model also helps us understand that technology is not a simple panacea for remediating performance problems. For example, if the issue is really that the individual lacks the incentive to complete an academic task (\#2), performance may not improve despite the availablility of a technology tool (\#4). Likewise, when a tool (\#4) is available only in one environment (\#5), performance gains will be limited.

When a student with mild disabilities encounters difficulty in the academic environment, Wile's model illustrates the array of interventions that should be assessed. For example, when a student with a disability has demonstrated chronic inability to memorize the multiplication facts, such that it is interfering with his or her performance in math class, teachers have a number of options to explore. If the child's IQ (\#7) suggests that he or she is capable of memorizing the facts, changes in instructional interventions (\#6) are warranted.

Likewise, changes in the organizational structure may be considered (\#1) (i.e., number of problems to practice, alter the types of instructional materials used, or change teachers to find a more compatible personality or classroom structure), as well as changes in settings (\#5), or various incentive/motivational strategies (\#2). If all of these interventions have yet to enhance the student's performance in applying his or her knowledge of the multiplication facts, however, two variables deserve further investigation: (\#3) cognitive support and (\#4) tools. In this case, the child's performance relative to using multiplication facts in the math classroom clearly could be enhanced by the use of a multiplication table (\#3) or by using a calculator (\#4).

Models of human performance can contribute to the development of performance support strategies that utilize technology. Specifically in Wile's model, variables \#3 (cognitive support) and \#4 (tools) suggest the value of identifying devices and tools that augment and extend cognitive functioning as a strategy for enhancing performance. One powerful example of a cognitive support stategy has been described by Edmunds (1999) in the form of "cognitive credit cards." Students are encouraged to create their own performance support card, the size of a credit card, and utilize this information whenever they bring it to class.

By understanding the many variables that affect performance, we are less likely to view technology mistakenly as a panacea for performance problems. With this perspective, we shall now turn our attention to exploring how various forms of assistive tchnology can contribute to the enhanced performance of students with mild disabilities.

\section{Reconceptualize the Forms of Assistive Technology}

When human performance is the primary focus, the definition of assistive technology is necessarily broad as we seek to use any and all conceivable resources to enhance performance. Although the application of assistive technology is apparent in situations involving impairments that limit mobility, sensory perception, and communication, what does it mean to enhance the performance of a learner?

One model of learning suggests that learners pass through a series of stages in the process of acquiring knowledge (Hasselbring \& Bottge, 2000; Mindscape, 1988).

1. The entry level is characterized by the learner performing the targeted task infrequently or not at all.

2. During the acquisition stage, the learner performs the task initially at $0-25 \%$ accuracy and moves to more advanced level when the task is performed with $65-80 \%$ accuracy.

3. The next stage, proficiency, seeks to develop fluency (high rate and high accuracy) in performing the task.

4. Retaining a high level of accuracy and rate is the primary consideration of the maintenance stage.

5. At the generalization stage, the learner is encouraged to transfer his or her knowledge to new settings as a means of applying what has been learned to new situations.

6. Finally, the adaptation stage is characterized by problem solving as the learner's knowledge is applied to novel problems.

Hasselbring, and Bottge (2000) have noted that the stages of acquisition and fluency are particularly problematic for students with special educational needs.

Although technology can be used in every stage of the learning process (i.e., applications of technology that enhance teaching and learning), when technology is utilized in ways that make a difference (quantifiable or qualitative) in performance, it can function as assistive technology. Consider a student with learning disabilities who participates in 
an inclusion science class and is having difficulty balancing chemical equations. Her teacher, concerned about the student's poor performance, has created a spreadsheet that structures the procedure into a series of steps and provides feedback to the student when she enters a value into an equation. Though such an intervention might be considered "just good teaching," in the performance support literature it is considered a "job aid." In the context of high-incidence disabilities, it is an example of an instructional support strategy.

For some students, this intervention will serve a transitional function helping them to understand the concept in more concrete terms and once they "get it," they will no longer utilize the spreadsheet but, instead, will be able to compute the calculations by hand, on paper, like most of their classmates. For some students, however, this spreadsheet is an example of assistive technology. The value of assistive technology is clearly demonstrated when assessing the student's performance under two conditions: completion of a specific task with the assistive technology, and completion of the same task unaided.

At this point, the distinction between instructional goals and functional outcomes should be highlighted. Wile's (1996) model of human performance helps us see the critical distinction between instructional technology and assistive technology. As long as the educational team seeks to employ various teaching and learning strategies, the application of technology is clearly instructional: We are explicitly seeking to enhance a student's skills and knowledge (\#6), an intrinsic variable that affects performance. This has been the historical emphasis of education-to increase the information and knowledge that we intrinsically carry with us. The value of such knowledge is clear in terms of portability and ready-access.

But what happens to students when they have difficulty learning or recalling critical information? Clearly, these learning problems have a negative impact on an individual's performance. As Johnson observed, knowledge is of two types: the kind you know, and the kind you know how to find (Boswell, 1887). When the focus shifts from teaching the skill to emphasizing a functional outcome (performance), the use of technology changes from instructional to assistive.

In considering the needs of students with mild disabilities for assistive technology, additional research and development is needed to identify devices and tools that augment and extend cognitive functioning as a strategy for enhancing performance. These applications have been referred to previously as "cognitive technologies," "intelligence extenders," "cognitive workbenches," or "mental prostheses" (Office of Technology Assessment, 1988).

Must a specific product be either instructional technology or assistive technology? For example, the program Inspira- tion (Inspiration Software) is commonly used in both special and general education as an alternative to outlining. This program allows users to enter individual ideas within a menu of shapes (e.g., circles, boxes) anywhere on the screen as part of their brainstorming efforts. After enough ideas have been generated, connections can be made by dragging the images around the screen and linking ideas.

The result is a visual map of the relationships among the key concepts. Is Inspiration an example of instructional technology because it helps students plan better writing projects, or is it an example of assistive technology because a student is unable to use any other method for planning a writing project?

As we have discussed, there is a fine line between instructional technology and assistive technology, and actually the same product could function as both depending on how it is used. Additional research and development are needed in the area of job aids, as they can be used to support learners in the acquisition and fluency phases of learning as well as other forms of mental prostheses to support the application of assistive technology for students with mild disabilities.

\section{Redesign Assistive Technology Service Delivery Systems}

In some professions, the tools of the trade have been defined historically. For example, the essential tools of carpenters and blacksmiths have changed little in the past several hundred years, and tools commonly are passed down from generation to generation.

In other fields, the introduction of new technologies has fundamentally altered the workers' basic toolkit and provides powerful illustrations of technology-enhanced performance. Consider the following examples:

- Developed around the knowledge of expert automative mechanics, comprehensive automative troubleshooting sytems facilitate the work of automative technicians by diagnosing problems in a car's engine and suggesting repair procedures.

- Electronic spreadsheets allow financial managers to change one figure and examine the impact of the change on all facets of a financial plan. This process of engaging in "what-if" calculations is further enhanced by dynamically displaying the results in a graph.

- Computer-assisted design (CAD) systems have fundamentally altered the work of architects and product designers by reducing the time involved in creating original designs and eliminating the laborious effort involved in preparing modifications.

- Bar-code systems enable express mail companies to track millions of products daily, have instant access to the whereabouts of any package in the system, and design optimal routes to ensure on-time delivery. 
Notice how in each case the outcome of enhanced performance can be understood through the SETT framework (Zabala, 2000), relative to understanding critical components related to the student (in this case, worker), the environment, the task, and the tools. In each situation, technology is effective, essential, and enhances performance. Therefore, in special education, why can't we present similar cases in which students have used technology effectively to enable them to achieve high academic standards?

As noted earlier, current service delivery systems for providing assistive technology services in schools does not seem capable of being scaled-up to meet the needs of students with high-incidence disabilities. Therefore, a new system has to be developed wherein the first step in accessing assistive technology devices and services is not a referral for an in-depth evaluation using a process that mirrors the traditional model of special education referral and placement.

An alternative to the current system involves creating and disseminating three types of toolkits that have been designed to enhance performance in teaching and learning. The toolkit is a helpful metaphor for understanding the potential of assistive technology for students with mild disabilities for several reasons.

1. It requires a clear understanding of the performance demands so as to stock the toolkit with the appropriate tools.

2. It recognizes that the user's skill impacts the production of high-quality outcomes more than the price of the tool or whether it is the latest model.

3. The toolkit is a container that effectively requires the user to make choices and set limits from among the overwhelming number of products in the marketplace.

4. A toolkit is portable and is readily available when the need arises.

Technology toolkits have been viewed as an increasingly popular technology integration strategy (Caverly, Peterson, \& Mandeville, 1997; Edyburn \& Gardner, 2000; McGillivray, 1999).

The toolkit approach is a proactive strategy for meeting the assistive-technology needs of students with mild disabilities. It serves to quickly deploy tools of obvious value into the hands of teachers and students. Ready access to technology tools and productivity strategies will provide opportunities for exploratory use and the collection of performance data. This approach links instruction, assessment, and prereferral strategies into an ambitious proposal to meet the highincidence needs of students with mild disabilities. Three kinds of toolkits that individually and collectively suggest an approach to assistive technology consideration for students with mild disabilities are: toolkits for teachers, assistive technology core toolkits, and learner productivity toolkits.

\section{Toolkits for Teachers}

An important strategy for improving educational outcomes focuses on enhancing teachers' professional development. Much of what students are able to accomplish, or not, is related directly to the competencies of their teachers. As a result, it is vital to develop technology toolkits that equip teachers with the tools necessary to support the diversity of student abilities found in inclusive classrooms.

The challenge of identifying and validating toolkits and productivity strategies that support the work of special education and related services personnel is one that has interested me for some time. To date, visions of essential tools have been advanced for professionals in several roles: speech therapist (Holt \& Edyburn, 1998), occupational therapist (Fenema-Jansen \& Edyburn, 1998), and assistive technology specialist (Kaplan \& Edyburn, 1998). Additional work is needed to advance and validate a common vision concerning the technology toolkit that enhances the performance of general and special education teachers in ways that foster higher levels of student achievement.

In my work, I encourage general and special education teachers to explore how a few tools (i.e., word processor, e-mail, web browser, and presentation software) and specific productivity skills can enhance teaching and learning in inclusive classrooms:

1. Learn how to take advantage of copy/cut and paste. Many teachers are familiar with the technique of copying or cutting and pasting within their word processor. Typically, this technique is applied to a word or phrase within a document to move text from one place to another. But did you know that this same skill can be used to move text from one document to another? Consider the value of this time-saving technique for constructing a quiz by copying and pasting selected items from old test files. Likewise, copy/cut and paste works with graphic images. In fact, copy/ cut and paste can be used to move information between any programs on the desktop.

2. Explore the collection of assistants, wizards, and templates in your integrated software package (e.g., Microsoft Office, ClarisWorks). Learning to use these tools will save you considerable time in producing high-quality materials.

3. Use clip art images to enhance your instructional materials. Hundreds of thousands of images are available on CD-ROM collections of clip art, and more can be downloaded from the Internet.

4. Use a screen capture tool (e.g., Screen Thief 98, FlashIt, Snapz Pro) to take a picture of an image on your 
computer screen. Now you can paste this image into a handout to show students what they can expect to see as they complete an assignment on the computer.

5. Use a digital camera to obtain images that are instructionally relevant for your students. Create a digital library of your images so you can copy and paste them into your instructional materials.

6. Learn to conduct web searches using specialized and innovative search tools such as Google (htp: //www. google.com), Ask Jeeves (http://www. aj.com), or The Gateway to Educational Materials (http://www.the gateway.org) and web browser add-ons such as Alexa (http://www.alexa. com). Finding more relevant information in less time is always a timesaver.

7. Learn how to create a web page using TrackStar (http://scrtec.org/track/). This free, easy-to-use tool enables teachers and students to create web pages with links and descriptions - a valuable alternative to written reports for students and a helpful management resource for teachers who want to make web pages for their students but don't have time to learn a web page authoring program.

The toolkit for teachers outlined above offers limitless possibilities for modifying both curriculum and instruction. Still, enhanced performance is not simply a function of the quality of the toolkit. It is the result of the skills of general and special education teachers in creatively and skillfully applying their tools and talents to help students achieve high academic standards. Nonetheless, the identification and validation of time-saving tools that enable teachers to modify and customize instructional materials for students with mild disabilities seems to be an investment that can reap significant dividends.

\section{Assistive Technology Core Toolkits}

Many special educators encounter a common instructional challenge posed by students who have difficulty developing their writing skills. The "traditional toolbox" that teachers have used to deal with this instructional problem has included textbooks, reference books, paper, and pencil. In contrast, a "technology toolbox" offers possibilities such as hand-held spelling checkers, predictive word processors, talking word processors, electronic thesarus, prewriting software, concept mapping software, graphic writing environments, telecommunications, desktop publishing tools, web publishing, and video production tools.

In any given year, teachers will work with students who have difficulties in written expression or can't read at grade level. As a result, why not equip each classroom with an assistive technology core toolkit that anticipates the needs of individual children based on the common characteristics of mild disabilities? The concept of an assistive technology core toolkit is a proactive strategy that offers a viable alternative to referring students for assistive technology evaluations as a first step in the process of assistive technology consideration.

What might an assistive technology core toolkit contain? The toolkit might include a word prediction word processor (e.g., Co:Writer) for students whose keyboarding skills are slow or limited. A text-to-speech scanner and speech output software (e.g., Wynn, eReader) would enable students who couldn't read a passage in a textbook to place the textbook on the scanner and have the information scanned into the computer and then spoken to them using the computer's digitized speech synthesizer. Access to the Internet and specialized search tools such as Ask Jeeves for Kids (http:// www.ajkids.com) could help students with limited reading skills locate factual information they need to complete assignments in content-area classes. Of course, hand-held spelling checkers and calculators would be available for use as necessary. These are just a few of the many possibilities.

The profession would benefit greatly from research, debate, and discussion of how technology enhances cognitive performance. The process of developing an assistive technology core toolkit would be an invaluable contribution to the profession and could significantly enhance the educational performance of students with mild disabilities on a scale that can appropriately impact the high-incidence disabilities. In addition, the availability of the assistive technology toolkit would allow teachers to collect performance data regarding the value of specific tools for individual students.

\section{Learner Productivity Toolkits}

The notion of a learner productivity toolkit centers on the identification and use of a set of products that learners use routinely as they engage in the activities associated with learning (Edyburn, 2000a, 2000b). Although the strategy of building a personal toolkit to enhance productivity as lifelong learners is one that could could benefit all students, it has important implications for special education and related service personnel when considering how to help students with disabilities achieve high standards. For example, if every inclusive classroom were equipped with a learner productivity toolkit specifically designed to meet a range of needs and abilities, the demarcation between assistive and instructional technology would blur, allowing renewed emphasis on performance and achievement.

Given the challenge of building a technology toolkit that supports students with special needs in inclusive settings, what would you include? Thinking about a middle school student with learning disabilities, below are some ideas I'd 
consider for creating a toolkit that enhances learner productivity (also see Table 3 ).

\section{Organizational Skills}

Teachers report that organizational difficulties are a problem for many students - one that negatively impacts their schoolwork. Personal planning systems illustrate the life-long

\section{TABLE 3}

\section{Learner Productivity Toolkit}

\section{Reading}

- Quicktionary Reading Pen (Wizcom)

- Speaking and Spelling and Handwriting Ace (Franklin Electronic Resources)

- Talking Text Conversion Station

$$
\begin{aligned}
& \text { - Scanner } \\
& \text { - Text-to-speech software } \\
& \text { eReader (CAST) } \\
& \text { WYNN (Arkenstone) }
\end{aligned}
$$

\section{Writing}

- Inspiration (Inspiration Software)

- Word Processor

$$
\begin{aligned}
& \text { - common } \\
& \text { Microsoft Word } \\
& \text { ClarisWorks }
\end{aligned}
$$

- Word Prediction Co:Writer (Don Johnston)

- Voice Input ViaVoice (IBM) Dragon Dictate (Dragon Systems) Naturally Speaking Voice Xpress (Lernout \& Hauspie)

- Speech Output Write:OutLoud (Don Johnston)

\section{- Reference Tools}

- Electronic Encyclopedias

- Ask Jeeves for Kids (http://www.ajkids.com)

- Publishing

- Microsoft Publisher (Microsoft)

- HyperStudio (Havas Interactive)

- TrackStar (http://scrtec.org/track/

\section{- Presentation}

$$
\text { - PowerPoint (Microsoft) }
$$

\section{Math}

\section{- Calculator}

importance of using an organizational system to enhance personal productivity; DayRunner (http://www.dayrunner.com) and FranklinPlanner (http://www.franklincovey.com) are examples. When an individual has regular access to a computer, computer-based day planners such as AnyDay (http:// www.anyday.com) and My Yahoo! (http://my.yahoo.com) also may be useful.

One of the trendiest applications of personal-productivity technology is the Palm Pilot (http://www.palm.com). Palm users can carry this portable hand-held device around and enter information with a stylus. At the end of the day, the information can be synchronized with a software version on the computer.

Remembering important deadlines or events is another element being organized. Remind U-Mail (http://calendar. stwing.upenn.edu) is a free service that allows users to create a calendar of important events and set a schedule for the system to automatically send an e-mail message with a reminder notice.

Mr. Wake-Up (http://www.mrwakeup.com) is another reminder system, part of a suite of products from the folks at iPing.com. Users register for this free system and, via a web page, enter their wake-up message, a delivery date and time, and a phone number. At the designated time, Mr. Wake-Up calls and speaks the wake-up message or reads the day's headlines, weather forecast, or other information.

The rest of the family includes Ms. Reminder, Mr. Notify, Ms. Followup, Dr. Dose, and Mr. Dollar. iPing describes their focus as "time-sensitive notifications via a range of devices." Users can elect to have their messages delivered via telephone, cell phone, pager, e-mail, or personal digital assistant. These services seem to have considerable promise for classroom and supported employment applications.

\section{Reading}

If a student has difficulty reading content-area textbooks, tools such as The Reading Pen (Wiscom) and the Speaking and Spelling and Handwriting Ace (Franklin) enable the user to enter an unknown word and hear a definition.

Another strategy involves creating a "talking text conversion station" using (a) a scanner, (b), Optical Character Recognition (OCR) software, and (c) text-to-speech software such as Wynn (Arkenstone) and eReader (CAST) support scanning text from a textbook into the computer so the student can listen to the material as the computer reads it.

\section{Ready Reference}

An important component of many learning activities is to consult reference sources. This is where access to the World 
Wide Web is invaluable. Popular ready reference sites include, among others, Ask Jeeves for Kids (http://www.ajkids. com), Online Calculators (http://www-sci.lib.uci.edu/HSG/Ref Calculators.html), General Reference and Study Skills Sites (http://www.teleport.com/ burrell/reference.phtml). One interesting interface design can be found at http://lightspan.com. When users click on the Study Scout icon, a separate browser window is opened with icon access to a calculator, dictionary, thesaurus, encyclopedia, maps, and the CIA World Fact Book.

\section{Writing}

Writers of all ages and abilities often have difficulty coming up with ideas and organizing their thoughts. Traditionally, the planning tool for this task has been the outline. The software product Inspiration (Inspiration Software), offers an alternative called concept mapping.

The basic tool for all writers is the word processor. Common word processors are Word (Microsoft) and ClarisWorks (Apple Computer). For writers who need additional support, three strategies are commonly utilized.

1. Word prediction products such as Co:Writer (Don Johnston) utilize artificial intelligence techniques to predict the word that is being entered so as to speed the text production process.

2. Voice input products such as ViaVoice (IBM), Dragon Dictate (Dragon Systems), and Voice Xpress (Lernout \& Hauspie) enable users to dictate their ideas and have the computer do the typing for them.

3. Speech output products such as Write:OutLoud (Don Johnston), Wynn (Arkenstone), and eReader (CAST) enable students to listen to what they have written.

Publishing is considered the final phase of the writing process. Writers have many options in this area as they focus on the visual presentation of their message. Core tools for publishing frequently involve clip art, Microsoft Publisher (Microsoft), and either HyperStudio (Havas Interactive) or PowerPoint (Microsoft). Both HyperStudio and PowerPoint have support features that allow the user to publish a slide show to the web. When reports can take the form of a web page, tools such as TrackStar (http://scrtec.org/track/) simplify the process.

\section{Math}

Just as the word processor is the fundamental tool for writers, the calculator is the fundamental tool for anyone working with numbers. For students who need additional supports, computer-based calculators such as Big:Calc (Don Johnston) and MathPad (InfoUse) can be valuable. Products such as Number Concepts $1 \& 2$ (Intellitools) conveniently support new math curriculua by offering math manipulatives, direct instruction, and computation support in an electronic environment.

\section{Study Strategies}

An important component of helping students improve their academic performance involves direct instruction in effective study-skill strategies. Many colleges have designed web sites to support students by providing a comprehensive collection of strategies, tools, and resources for fostering effective study skills. Two favorite sites include The Study Strategies Home Page from the University of Minnesota Duluth (http://www.d.umn.edu/student/loon/acad/strat/) and Study Guides and Strategies from St. Thomas (http:// www.iss.stthomas.edu/studyguides/). At the K-12 level, Lynne Anderson-Inman has validated a series of computerbased study skill strategies and made the high-quality materials available at her web site as downloadable resources (http://npip.com/CBSS/sampler.htm).

Among the variety of web sites that have been created especially to help students with their homework are: Yahoo! Reference (http://dir.yahoo.com/reference/index.html); StudyWEB (http://www.studyweb.com/); John December's List of Essential Resources (http://www.december.com/cmc/info/); High School Hub (http://www.highschoolhub.org/hub/hub.htm); The Writer's Center: Resources for Writers and Teachers (http://www.colostate.edu/depts/WritingCenter/tools.htm) ; Dave's Math Tables (http://www.sisweb.com/math/tables.htm); and Schoolwork.Org (http://www.schoolwork.org/index.html).

The design, validation, and dissemination of technology toolkits is a strategy with the potential to provide an alternative to the current sytems of accessing assistive technology services for students with mild disabilities. Next we will examine the issue of accountability so we can make decisions about the effective use of assistive technology.

\section{Respond to the Need to Document the Impact and Effectiveness of Assistive Technology}

In recent years, schools have demonstrated a willingness to devote more of their budget to the purchase of assistive and instructional technology, but there is little evidence documenting the impact of these expenditures. Because of the scale and scope of the issues involved in acquiring and implementing assistive technology for high-incidence mild disabilities, accountability considerations must be addressed.

Particularly troublesome for the profession are statements like the following: "Jimmy doesn't write very well, I think he could benefit from having a laptop computer." How do we decide who needs a calculator? A laptop computer? And who doesn't? 
For the most part, the efforts of the educational community over the past decade to acquire hardware and software have been successful (Bruder, 1993; CEO Forum 1998, U.S. Department of Education, 1998). The 1990s can be viewed as a period of profound infrastructure building as powerful desktop computers have been purchased, local area networks have been installed to connect computers throughout the school building, and Internet access has been acquired.

Few voices have challenged the general trends in the acquisition of technology that were apparent in schools during the late 1990s. Given the massive investment in technology, however, what effect has it had on teaching and learning? Educators and policymakers have been asking this question more often. Several recent initiatives suggest a new era of accountability and technology in education as tools are being developed to evaluate levels of technology integration and the impact of technology on learning (Anneberg Institute of School Reform, 1999; CEO Forum, 1999; Milken Exchange, 1999; SEIR•TEC, 1999).

Questions of effectiveness also have been raised in the context of assistive technology, especially as the field struggles with how to assess and implement specialized devices for high-incidence disabilities when the current delivery systems have struggled under the workload of providing these services for low-incidence disabilities.

In contrast to the abundance of measures and indicators that profile the acquisition of technology, less information is typically available to reflect progress toward implementing technology applications that enhance teaching, learning, and performance. Historically, questions about the effectiveness of specific educational interventions prompt us to turn to the educational research literature for answers.

Often, the research literature is a less than satisfying resource to document the effectiveness of special education technology products in the marketplace. Part of the problem is the rapid pace of development and the natural consequence of educational products being developed and brought to market without a research base to demonstrate the effectivness of the intervention. Even when research is available, it may be less than satisfying for our needs. To understand why, we will examine the interaction among three related issues: claims, evidence, and decision-making.

\section{Claims}

A natural part of marketing involves making claims about a product. In many cases, the claims are modest: "This product will help students ..." In other cases, they border on the outlandish: "After using this product for 2-4 weeks, students will demonstrate 2 years' gain in reading comprehension." Although little can be done to prevent such ambitious claims, the educational community must carefully examine the claims to discern factual statements about intended outcomes, effectiveness, and impact.

\section{Evidence}

I've found it helpful to think of questions about the effectiveness of a technology intervention as falling somewhere on a continuum (see Figure 3 ). On the far right side of the continuum, effectiveness is unknown; at the far left side, effectiveness is known. As we evaluate claims of effectiveness, it seems to me that the decision-making process is fundamentally about the level of confidence we want to have in the evidence presented to us. Thus, it really doesn't matter where we start on the continuum; we are simply trying to make incremental moves to the right to give us the confidence we need.

Some types of evidence that might be presented in support of a claim of effectiveness are the following:

Intiuitive. One type of evidence is distinguished by the lack of data to support the effectiveness of a claim. In this situation, statements such as, "I don't know why it works, I just know it does" are common. Obviously, these claims are unacceptable because the observer is unable to point to any measurable outcomes that can be independently reviewed by others. Because this evidence cannot be documented, these types of claims usually are not found in print but, rather, are shared orally.

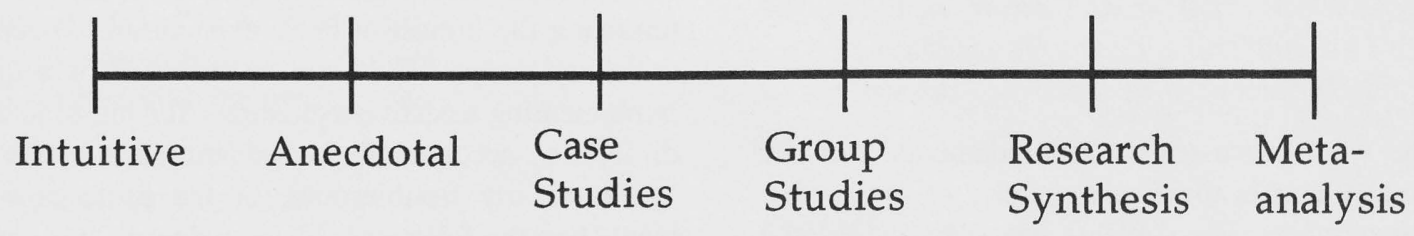


Anecdotal. Another form of proof that a given intervention is effective comes in the form of anecdotal evidence. Commonly, this consists of disparate indicators: The student indicates he likes using the tool, school attendance has improved, and off-task behavior is lower when the child uses a software program than when he completes comparable activities at his desk. Taken together, the indicators may suggest a pattern of the power of the intervention. In this context, data are not collected systematically but in many cases could be retrieved to document and support the observations.

Anecdotal evidence is a higher standard than a simple report of "it works for me." In practice, anecdotal evidence often is the highest level of test to which we subject a claim because of limited time and resources for more formal evaluation procedures.

Single-Study Research or Case Studies. Single-subject research and case studies utilize slightly different methodology but share a primary characteristic-focus on a single unit (e.g., student, classroom, school). Here we can see the rudiments of research: reliable procedures, systematic collection of data, data analysis, and reporting of the results. This type of evidence represents a quantum leap for the confidence in our decisions over the previous two forms.

Single-subject research is highly prized in special education as a tool for studying individuals because change is measured against the individual's previous performance without regard for groups. This characteristic also can be viewed as a limitation by those who want group measures: "They only studied one student!"

Group Studies. Research studies that examine the effectiveness of an intervention with groups of students are noteworthy in supporting a claim of effectivness in that a well designed study leads to generalizations that can be made from the sample to a population. Although a single study often does not provide a definitive statement, it does represent a significant level of confidence. Multiple studies on the same topic strengthen the findings of an individual study and serve to build the professional knowledge base.

Research Synthesis. As a body of research grows, a synthesis of the literature becomes a viable option. Unfortunately, it often takes many years to build up an adequate base of research studies to make generalizations. Several notable works inform special education technology efforts: Becker (1991); Okolo, Bahr, and Rieth (1988); Woodward and Reith (1999); Roblyer, Castine, and King (1988); and SivinKachala, and Bialo (1995).

Meta-analysis. Perhaps the highest level of evidence we can gather regarding the effectiveness of an intervention involves a statistical procedure known as meta-analyis. This procedure requires systematically gathering and coding the results found in various research studies on a topic and then computing a statistic that represents the combined finding of the impact of the intervention as measured in all the studies. Meta-analysis studies that can inform the work of special educators have been completed by Fletcher-Finn, and Gravatt (1995) and Goforth (1994). Early studies by Kulik and colleagues (Kulik, Bangert, \& Williams, 1983; Kulik, J., Kulik, C., \& Bangert-Drowns, 1985) are often still cited but of dubious value given the fact that much of the original research was completed on mainframe computer systems prior to 1985 .

\section{Decision-making}

Ultimately, we make decisions to acquire and implement technology as an investment in some anticipated outcome(s) that we'd like to see happen. Sometimes decisions are made in the absence of data or proof of effectiveness. In other cases, because of the cost, scale, or scope of the implementation we desire, we require a considerable body of evidence to make decisions with confidence. Thus, additional attention has to be devoted to understanding who makes decisions about assistive technology and how much information is required for informed decision-making. Some common decisions are outlined below.

No-data-required Decisions. Factors other than student achievement (such as what's popular) influence these decisions. Of course, the decisions are not likely to significantly impact student achievement.

Inexpensive Decisions. If a product is inexpensive, we sometimes forego any analysis or review in favor of simply "buying and trying it out." Indeed, impulse buying is common when visiting a computer store or browsing a catalog. After the try-out period, we either decide we like the product and continue to use it or we discard it with little guilt ("It wasn't too expensive"). In either case, the tool has proven its value (or not) through our personal but informal assessment. We need no higher level of proof.

Infrastructure Decisions. Sometimes decisions are made on the basis of concerns (e.g., administrative mandate, improving technical support) other than an interest in student achievement. For example, consider the decision of whether to upgrade the Windows operating system from Windows 95 to Windows 98 . That decision is unlikely to be evaluated in terms of its impact on student learning and whether the funds could be used more appropriately to purchase instructional software. In situations like this, factors other than instructional effectivness are driving the decision-making.

Marketplace Deference Decisions. Haines (1999) has suggested another way of knowing about effectiveness. He offered the concept of "cash validity," suggesting, as proof 
that a product is effective, that it is a best seller in the marketplace. In this case, sales data are used as a proxy for research-based data on the product's effectiveness.

Decisions with Accountability. Finally, some decisions are made with an explicit concern about accountability. Indeed, at this level, attention is devoted to the effectiveness of the product or intervention. Special educators, however, must be wary of practices that hold students with disabilities to a different standard. It is particularly troublesome to hear of situations in which school boards are asking for detailed analyses to justify the purchase of a $\$ 3,000$ assistive technology device while making other decisions to spend $\$ 60,000$ to upgrade software with little more than a two-sentence justification.

Zabala and Korsten (1999) have suggested that a series of changes can be expected when assistive technology is used effectively: quality, quantity, accuracy, rate, frequency, spontaneity, and independence. These indicators provide a useful framework for developing a measurement and decision-making system concerning the effective use of assistive technology.

In the following list, I've linked the indicators with measurement strategies and decision-making questions to guide our emerging accountability efforts:

\section{Indicator: Quality}

If the student peforms the desired task with output considered to be of an inadequate quality, can assistive technology enhance the quality of the output?

Measure: Baseline sample of unaided task completion Quality assessment of task completion with assistive technology

Decision: Is the outcome quantifiably better when the student uses assistive technology to complete a task than when the identical task is completed unaided?

\section{Indicator: Quantity}

If the student's performance is characterized by inadequate quantity of output, can assistive technology enhance the quantity of output?

Measure: Baseline sample of unaided task completion Quantity assessment of task completion with assistive technology

Decision: Does the student quantitatively produce more when using assistive technology to complete a task than when the identical task is completed unaided?

\section{Indicator: Accuracy}

If the student performs the desired task with low accuracy, can assistive technology enhance the accuracy of task completion?

\section{Measure: Pretest of unaided task completion Posttest of task completion with assistive technology}

Decision: Does the student demonstrate quantifiable improvement when using assistive technology to complete a task versus completing the identical task unaided?

Indicator: Rate

If the student peforms the desired task too slowly, can assistive technology enhance the rate of task completion?

Measure: Timed pretest of unaided task completion Timed posttest of task completion with assistive technology

Decision: Does the student demonstrate quantifiable reduction in the time required to complete a task when using assistive technology versus completing the identical task unaided?

Indicator: Frequency

If the student refrains from performing the desired task, can technology be used to enhance engagement?

Measure: Baseline observation and event recording of engagement in the desired task

Follow-up observation and frequency count of engagement in the desired task with assistive technology

Decision: Does the student demonstrate quantifiable improvement when using assistive technology to engage in a task versus completing the identical task unaided?

Indicator: Spontaneity

If the student fails to spontaneously engage in the desired task, can technology be used to enhance engagement?

Measure: Baseline observation and event-recording of spontaneous engagement in the desired task

Follow-up observation and frequency count of spontaneous engagement in the desired task with assistive technology 
Decision: Does the student demonstrate quantifiable improvement when using assistive technology to spontaneously engage in a task versus completing the identical task unaided?

Indicator: Independence

If the student is unable to perform a desired task independently, can assistive technology enhance independence?

Measure: Baseline observation and frequency count of supportive interventions while completing the desired task

Follow-up observation and frequency count of supportive interventions while completing the desired task with assistive technology

Decision: Does the student demonstrate quantifiable improvement in independently completing a task when using assistive technology versus completing the identical task unaided?

A form like the one illustrated in Figure 4, can assist in the accountability process by creating a framework for guiding data collection, evaluation of performance, and assistive technology decision-making.

The measurement strategies and decision-making frameworks described here constitute an essential step toward

\section{Assessing the Effectiveness of Technology-Enhanced Performance}

Question/Claim:

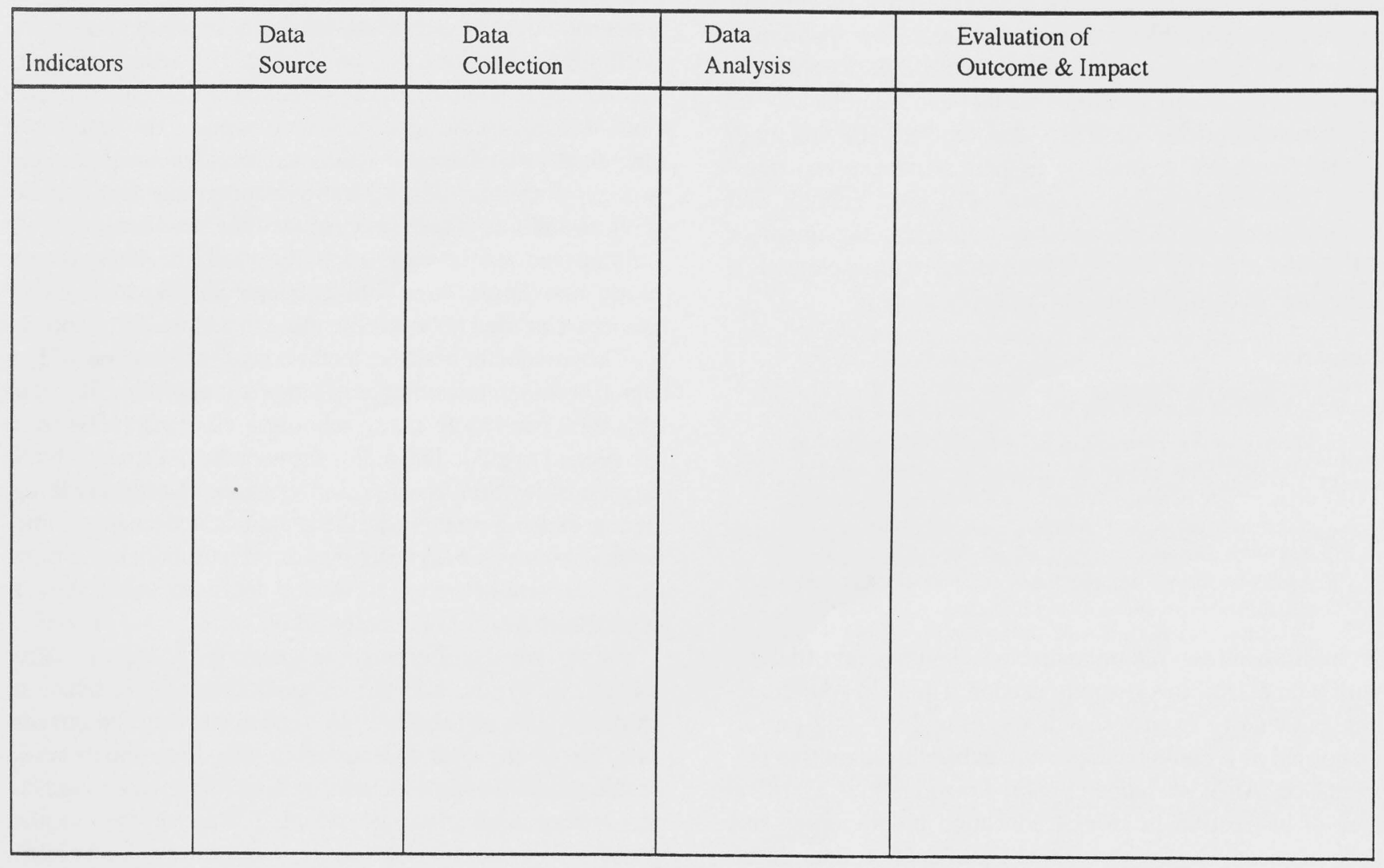


demonstrating the accountability and effectiveness of assistive technology, but much remains to be done. For example, currently we do not know what kinds of increases (e.g., $20 \%, 50 \%$ ?) can be reasonably expected in functional performance as a result of using assisțive technology. Also, it would be valuable for the profession to have access to standard data-collection protocols that would facilitate data collection and decision-making relative to each type of outcome indicator. Given that the requirement for assistive technology consideration does not come with a blank check, a significant commitment must be made to developing the assessment protocols and professional conscensus on how to interpret the data so we can reliably assess the need for assistive technology. Likewise, we will need to make decisions about students who are unlikely to benefit from assistive technology.

\section{IMPLICATIONS FOR RESEARCH, POLICY, AND PRACTICE}

The field of assistive technology has witnessed significant advances in recent years, in part because of federal policy inititatives that have sought to maximize the potential of technologies available in the marketplace. The application of assistive technology for students with mild disabilities, however, is a recent development that can be linked to the 1997 reauthorization of IDEA that requires IEP teams to consider assistive technology as part of educational planning. Anecdotal evidence suggests that most schools and many districts are ill prepared to implement the intent of IDEA that each IEP team consider assistive technology as it plans the educational program for every student.

\section{Research}

Hannaford (1993) observed:

\begin{abstract}
Much of what is presented as being known about the use of computers with exceptional persons is actually what is believed, felt, or hoped. While there is an increasing amount of research and evaluation support associated with various uses of the technology, there is still relatively little empirical support for many statements found in the popular literature. (p. 12)
\end{abstract}

Additional research on assistive technology and students with mild disabilities is sorely needed. The field would benefit particularly from research on technology as a performance aid as it could be applied to enhancing cognitive performance. Also, social/behavioral functioning is a critical area of instruction in special education programming that does not seem to have generated significant product development or interventions.

Research on assistive technology outcomes is also a critical need for the field. What difference does assistive technology make? Are some implementations more effective than others?

New approaches to technology research also could be helpful. The current model of releasing a request for proposals (RFP) and then funding a project a year later for 3 years is not a process that can keep pace with the changes in the marketplace. By the time the research is published, a conservative estimate of 5 years after initial funding, it is not likely to be relevant given annual software update cycles and yearly hardware advances. Thus, we have a clear difficulty in obtaining research that supports decision making concerning the effective acquisition and implementation of technology in special education.

\section{Policy}

A huge gap exists between visions of the potential of technology and the realities involved in capturing the potential of technology in solutions that work for individuals with disabilities. A variety of additional policies initiatives are urgently needed.

First, the federal government and state departments of education must recognize the critical shortage of personnel trained to utilize assistive technology in schools with students with mild disabilities. In the aftermath of reauthorization, technology must assume a more central role in the preparation of special education teachers because the legislation specifically requires IEP teams to consider assistive technology when planning educational programs for students with disabilities. There is an immediate need for inservice training and resources to meet the needs of students currently in schools. In addition, personnel preparation programs are needed to build a pipeline to address future needs.

The paradox of assistive technology consideration-How can I consider technology if I don't know what is available? - is paralyzing many school-based teams. New tools are needed to guide IEP teams through the assistive technology consideration process and enhance decision-making. One promising strategy is the creation of decision frameworks (Anison, 1992) utilizing a flowchart model to prompt users concerning key questions and decisions and then guiding them to possible interventions.

As described earlier, there is a need to redesign assistive technology service-delivery systems to meet the needs of students with mild disabilities. The current system that involves an in-depth assessment as the first step is not a viable model for high-incidence disabilities. Three types of technology toolkits comprise an alternative system that proactively seeks to make devices and interventions available as part of a massive network of prereferral interventions. Policy initiatives are needed to support and refine such a service delivery model. 
Given the sheer number of high-incidence disabilities, there is an immediate need for decision-making guidelines concerning how to document the need for assistive technology so it is possible to discern who can benefit and who cannot. Statements like "Jimmy does write very well; I think he could benefit from a laptop computer" have effectively stopped assistive technology consideration in many schools because of the fear of the cost associated with purchasing a laptop computer for 50 students like Jimmy.

\section{Practice}

The difficulties associated with technology integration are well documented and illustrate the complexity involved in capturing the potential of assistive technology for students with mild disabilities. Lack of teacher time; access to hardware, software, and support; limited leadership, lack of of a common vision or rationale for technology use; limited training and support; and the impact of current assessment practices on defining what teachers must teach and that what students learn with technology may not be readily measured on standardized tests (U.S. Congress, Office of Technology Assessment, 1995). Willis (1993) adds a number of other interesting dimensions of the problems: Curricular integration is a complex, difficult-to-learn process; many educators feel isolated and alone; time to experiment, explore, and study innovations is essential but rare in schools; top-down projects tend to fail over time; resentment and resistance destroy projects, ownership is critical to success; bottom-up projects tend to fail over time; administrative support is critical; nonexistent, inadequate, or inconsistent support is a major reason for failure; and theories of change are useful planning guides for change. Finally, experienced technology-using teachers conclude-at least initially - that most uses of computers make teaching more challenging and require more effort (U.S. Congress, Office of Technology Assessment, 1988).

Many questions remain with the goal of assistive technology consideration and the desire to help students achieve high academic standards: How can I consider technology if I don't know what is available? Given all the possibilities, where do I start? How do I know if a specific device is helpful? Necessary? Effective?

Validated interventions are essential. As it stands now, the toolkit approach is really a do-it-yourself model. If assistive technology is truly effective for students with mild disabilites, why can't the interventions be documented and disseminated? Professional development opportunities are called for. At the end of the article is a list of suggested readings and web sites that interested readers might find useful as a starting point for their assistive technology professional development.

\section{CONCLUSION}

Ever since the potential of technology for individuals with disabilities was demonstrated through case studies (Office of Technology Assessment, 1982), the field has struggled with the "scaling-up" challenge. How do we reach all the individuals who potentially could benefit from using a specialized device? The gap between the potential of technology and current practice has been a source of frustration to consumers, parents, professionals, and policymakers.

The issues confronting the profession concerning mild disabilities and assistive technology are significant, but the current state of affairs also provides opportunities. Four new directions seem to offer promise: recognizing the contributions and limitations of technology for enhancing performance, reconceptualizing the forms of assistive technology, redesigning assistive technology service delivery systems, and responding to the need to document the impact and effectiveness of assistive technology.

This work was supported in part by Grant \#H325H990144 from the Office of Special Education and Rehabilitative Services, U.S. Department of Education to the University of Wisconsin-Milwaukee. Points of view or opinions stated in this article do not necessarily represent official agency positions.

\section{REFERENCES}

AbleData. (2000). Search for assistive technology products. Available from: http//www.abledata.com/text2/search.htm.

Anneberg Institute of School Reform. (1999). Tools for Accountability. Available from: http://www.aisr.brown.edu/accountability/toolbox/default.html.

Anson, D. (1992). Finding your way in the maze of computer access technology. American Journal of Occupational Therapy, 48(2), 121-129.

Baily, R. W. (1989). Human performance engineering (2d ed). Englewood Cliffs, NJ: Prentice Hall.

Becker, H. J. (1991). How computers are used in United States schools: Basic data from 1989 I.E.A. computers in education survey. Journal of Educational Computing Research, 7(4), 385-406.

Behrmann, M. M. (1994). Assistive technology for students with mild disabilities. ERIC Digest E529, ERIC Document Reproduction Service, ED378755.

Blackhurst, A. E. (1997). Perspectives on technology in special education. Teaching Exceptional Children, 29(5), 41-48.

Blackhurst, A. E., \& Edyburn, D.L. (2000). A brief history of special education technology. Special Education Technology Practice, 2(1), 21-36.

Boswell, J. (1887). Life of Johnson. New York: Harper and Row.

Bruder, I. (1993), October). Technology in the U.S.A. Electronic Learning, 20-28.

Bryant, D. P., Bryant, B. R., \& Raskind, M. H. (1998). Using assistive technology to enhance the skills of students with learning disabilities. Intervention in School and Clinic, 34(1), 53-58.

Caverly, D. C., Peterson, C. L., \& Mandeville, T. F. (1997). A generational model for professional development. Educational Leadership, 55(3), $56-59$.

CEO Forum (1998). 1998 Star Chart: A tool for assessing school technology and readiness. Washington, DC: author. [also available: http://www. ceoforum.org].

CEO Forum. (1999). CEO Forum Star chart. Available from: http://www. ceoforum.org. 
Chambers, A. C. (1997). Has technology been considered? A guide for IEP teams. Reston, VA: The CASE/TAM Assistive Technology Policy and Practice Group.

Cook, A. M., \& Hussey, S. M. (1995). Assistive technologies: Principles and practice. St. Louis: Mosby-Year Book.

Derer, K., Polsgrove, L., \& Rieth, H. (1996). A survey of assistive technology applications in schools and recommendations for practice. Journal of Special Education Technology, 13(2), 62-80.

Edmunds, A. L. (1999). Cognitive credit cards: Acquiring learning strategies. Teaching Exceptional Children, 31(4), 68-73.

Edyburn, D. L. (1996). Assistive technology for students with mild disabilities. LRP Educational Technology Conference and Expo '96 Conference Proceedings, San Francisco.

Edyburn, D. L. (2000a). Learner productivity: A technology integration strategy for supporting students with special needs in inclusive settings, Closing the Gap, 19(1), 20-22.

Edyburn, D. L. (2000b). Interactive Study Tools. Closing the Gap, June/ July, 19(2), 22, 33.

Edyburn, D. L., \& Gardner, J. E. (2000). The use of technology to enhance professional productivity. In J. Lindsey (Ed.), Technology and exceptional individuals, (3d. ed. pp. 161-189). Austin, TX: Pro-Ed.

Fein, J. (1996). A history of legislative support for assistive technology. Journal of Special Education Technology, 13(1), 1-3.

Fenema-Jansen, S., \& Edyburn, D. L. (1998). Essential tools of the trade: An occupational therapist shares her tool kit. Closing the Gap, 17(4), 8-9, 32-33, 40 .

Fletcher-Finn, C. M., Gravatt, B. (1995). The efficacy of computer assisted instruction (CAI): A meta-analysis. Journal of Educational Computing Research, 12(3), 219-242.

Gilbert, T. F. (1978). Human competence: Engineering worthy performance. New York: McGraw-Hill.

Goforth, D. (1994). Learner control-decision making + information: A model and meta-analysis. Journal of Educational Computing Research, 11(1), $1-26$

Golden, D. (1998). Assistive technology in special education: Policy and practice. Reston, VA: CASE/TAM Assistive Technology Policy and Practice Group.

Golden, D. (1999). Assistive technology policy and practice: What is the right thing to do? What is the reasonable thing to do? What is required and must be done? Special Education Technology Practice, 1(1), 12-14.

Haines, L. (1999). Personal communication.

Hannaford, A. E. (1993). Computers and exceptional individuals. In J. D. Lindsey (Ed.), Computers and Exceptional Individuals (2d ed. pp. 3-26). Austin, TX: Pro-Ed.

Hasselbring, T. S., \& Bottge, B. A. (2000). Planning and implementing technology programs in inclusive settings. In J. D. Lindsey (Ed.), Technology and exceptional individuals, (3d ed. pp. 91-113). Austin, TX: Pro-Ed.

Holt, K., \& Edyburn, D. L. (1998). Essential tools of the trade: A speech language clinician shares her tool kit. Closing the Gap, 17(2), 11, 30, 33.

Hutinger, P., Johanson, J., \& Stoneburner, R. (1996). Assistive technology applications in educational programs of children with multiple disabilities: A case study report on the state of the practice. Journal of Special Education Technology, 13(1), 16-35.

Kaplan, M. W., \& Edyburn, D. L. (1998). Essential tools of the trade: An assistive technology specialist shares her tool kit. Closing the Gap, $17(3), 1,8,18,24$.

Kulik, J. A., Bangert, R. L., \& Williams, G. W. (1983). Effects of computerbased teaching on secondary school students. Journal of Educational Psychology, 75(1), 19-26.

Kulik, J. A., Kulik, C. C., \& Bangert-Drowns, R. (1985). Effectiveness of computer-based education in elementary schools. Computers in Human Behavior, 1, 59-74.

Mager, R. F. (1992). What every manager should know about training. Belmont, CA: Lake Publishing.

McGillivray, K. (1999). The toolkit: An innovative approach to technology integration in networked schools. Learning and Leading with Technology, 26(5), 18-21, 31 .
McGregor, G., \& Pachuski, P. (1996). Assistive technology in schools: Are teachers, ready, able, and supported? Journal of Special Education Technology, 13(1), 4-15.

Meese, R. L. (2001). Teaching learners with mild disabilities: Integrating research and practice. Belmont, CA: Wadsorth/Thomson Learning.

Milken Family Foundation. (1999). Milken Exchange Indicators. Available from: http://www.mff.org/edtech/

Mindscape. (1988). Curriculum methods for mastery. Or, how to make education special for all learners. City, State: author.

99 essential web sites for special educators. (1999). Special Education Technology Practice, 1(3), 12-17.

Okolo, C. M. (2000). Technology for individuals with mild disabilities. In J.D. Lindsey (Ed.), Technology and Exceptional Individuals, (3d ed., pp. 243-301). Austin, TX: Pro-Ed.

Okolo, C. M., Bahr, C. M., \& Rieth, H. J. (1988). A retrospective review of computer-based instruction. Journal of Special Education Technology, 12(1), 1-27.

Office of Technology Assessment. (1988). Power on! New tools for teaching and learning. Washington, DC: U.S. Government Printing Office.

Parette, H. P., \& Hourcade, J. J. (1997). Family issues and assistive technology needs: A sample of state practices. Journal of Special Education Technology, 13(3), 27-43

Parette, H. P., \& Hourcade, J. J. (2000). Assistive technology training for parents of students with disabilities. Special Education Technology Practice, 2(2), 20-24.

Raskind, M. H., Higgins, E. L., Slaff, N. B., \& Shaw, T. K. (1998). Assistive technology in the homes of children with learning disabilities: An exploratory study. Learning Disabilities: A Multidisciplinary Journal, 9(2), 47-56.

Roblyer, M. D., Castine, W. H., \& King, F. J. (1988). Assessing the impact of computer-based instruction. Computers in the Schools, 5(3/4), 1-149.

Rossett, A. (1992). Analysis of human performance problems. In Handbook of Human Performance Technology. San Francisco: Jossey-Bass.

SEIRTEC. (1999). SEIRTEC Technology Integration Progress Guage. Available from: http://www.seirtec.org/publications/guage6_0.doc.

Sivin-Kachala, J., \& Bialo, E. R. (1995). Report on the effectiveness of technology in schools, 1990-1994. Washington, DC: Software Publishers Association.

Spitzer, D. (1991). Introduction to instructional technology (2d ed.). Boise State University.

Todis, B. (1996). Tools for the task? Perspectives on assistive technology in educational settings. Journal of Special Education Technology, 13(2), 49-61.

Todis, B., \& Walker, H. M. (1993). User perspectives on assistive technology in educational settings. Focus on Exceptional Children, 26(3), $1-16$.

U.S. Congress, Office of Technology Assessment. (1982). Technology and Handicapped People. Washington, DC: U.S. Government Printing Office.

U.S. Congress, Office of Technology Assessment (1988). Power on: New tools for teaching and learning. Washington, D.C.: U.S. Government Printing Office. Also available at: http://www.wws.princeton.edu:80/ $\sim$ ota/ns20/catte_n.html.

U.S. Congress, Office of Technology Assessment (1995). Teachers and technology: Making the connection. Washington, D.C.: U.S. Government Printing Office. Also available at: http://www.wws.princeton. edu:80/ ota/disk1/1995/9541_n.html.

U.S. Department of Education. (1998). An educators guide to evaluating the use of technology in schools and classrooms. Available from: http://www.ed.gov/pubs/EdTechGuide/.

U.S. Department of Education. (2000). Twenty-first annual report to Congress on the implementation of the Individuals with Disabilities Education Act. Washington, DC: Author. Available online: httl://www.ed. gov/offices/OSERS/OSEP/OSEP99AnlRpt/

Wehmeyer, M. L. (1999). Assistive technology and students with mental retardation: Utilization and barriers. Journal of Special Education Technology, 14(1), 48-58.

Wile, D. (1996). Why doers do. Performance and Instruction, 35(2), 30-35. Willis, J. (1993). What conditions encourage technology use? It depends on 
the context. Computers in the Schools. 9(4), 13-32.

Woodward J., \& Reith, H. (1997). A historical review of technology research in special education. Review of Educational Research, 67(4), 503-536.

World Health Organization. (1980). International classification of impairments, disabilities, and handicaps. Geneva: Author.

Zabala, J. S., \& Korsten, J. E. (1999). Beyond “try it! you'll like it...or maybe you won't?": Making a measurable different with assistive technology. Preconference workshop handout, 1999 Closing the Gap Conference, Minneapolis.

Zabala, J. S. (2000). Joy Zabala's resources for assistive technology in education. Available from: http://sac.uky.edu/ jszaba0/JoyZabala.html.

\section{Books, articles, and web sites to assist readers in learning about issues related to mild disabilities and assistive technology.}

\section{Specific Disabilities}

Keel, M. C., Dangel, H. L., Owens, S. H. (1999).

Selecting instructional interventions for students with mild disabilities in inclusive classrooms. Focus on Exceptional Children, 31(8), 1-16.

Complete Disability Network

http://members.aol.com/disablenet/Main/DisableNet.html

The Cornucopia of Disability Information

http://codi.buffalo.edu/

\section{Historical Perspectives on Special Education Technology}

Blackhurst, A. E. (1997). Perspectives on technology in special education. Teaching Exceptional Children, 29(5), 41-48

Blackhurst, A. E., \& Edyburn, D. L. (2000).

A brief history of special education technology.

Special Education Technology Practice, 2(1), 21-36.

Fein, J. (1996). A history of legislative support for assistive technology. Journal of Special Education Technology, 13(1), 1-3.

Hannaford, A. E. (1993). Computers and exceptional individuals. In J. D. Lindsey (Ed.), Computers and Exceptional Individuals, 2nd ed, (pp. 3-26). Austin, TX: Pro-Ed.

\section{Policy/Legal Issues}

Etscheidt, S. K., Bartlett, L. (1999). The IDEA Amendments: A four-step approach for determining supplementary aids and services. Exceptional Children, 65, 163-174.

Galloway, J. P. (1990). Policy issues for learning disability implementation. Journal of Learning

Disabilities, 23, 331-334, 348.

The EdLaw Center

http://www.edlaw.net/

Americans with Disabilities Act Document Center http://janweb.icdi.wvu.edu/kinder/

Disability Related Issues:

A Web Pathfinder for Student Research http://www.disrights.org/guide/research.html

\section{Assistive Technology Implementation}

McGregor, G., \& Pachuski, P. (1996). Assistive technology in schools: Are teachers, ready, able, and supported? Journal of Special Education Technology, 13(1), 4-15.

Todis, B. (1996). Tools for the task? Perspectives on assistive technology in educational settings. Journal of Special Education Technology, 13(2), 49-61.

College Students with Disabilities and Assistive Technology: A Desk Reference Guide http://www.educ.msstate.edy/PAACS/ products/atg_guide.html

Education Tech Points

http://www.dinf.org/csun_99/session0089.html

\section{Assistive Technology Devices}

Closing the Gap Resource Guide http://www.closingthegap.corn

AbleData

http://www.abledata.com

\section{Consideration of Assistive Technology}

Family Guide to Assistive Technology http://www.pluk.org/AT1.html

Consideration: A detailed look http://www.rit.edu/ easi/akl2/kl2/kl2atiep.html

Joy Zabala's Resources for Assistive Technology in Education http://sac.uky.edu/ jszaba).JoyZabala.html

\section{Measuring Assistive Technology Outcomes}

RESNA. (1999). Volume 1,

RESNA Resource Guide for Assistive Technology

Outcomes: Measurement Tools; Volume 2 RESNA Resource Guide for Assistive Technology Outcomes: Assessment Instruments; Volume 3 RESNA Resource Guide for Assistive Technology Outcomes: Developing Domains of Need and Criteria of Services.

Arlington, VA: Author. 
Apple Computer, 1 Infinite Loop,

Cupertino, CA 95014; Phone 408-996-1010;

WWW <http://education.apple.com>

Ask Jeeves for Kids,

WWW <http://www.ajkids.com>

Don Johnston Inc. new address; Phone 800-999-4660;

Fax 847-526-4177; WWW

$<$ http://www.donjohnston.com>

Dragon Systems, Inc, 320 Nevada Street,

Newton, MA 02160; Phone 617/965-5200;

WWW <http://www.dragonsys.com>

Franklin Learning Resources, Franklin Plaza,

Burlington, NJ 08016-4907; Phone 800-266-5626;

WWW <http://www.franklin.com>

Havas Interactive, Inc, 4100 W. 190th Street,

Torrance, CA 90504; Phone 310-793-0600;

WWW <http://www.hyperstudio.com>

IBM Special Needs Systems, 11400 Burnet Road,

Austin, TX 78758; Phone 800-426-4832;

WWW <http://www4.ibm.com/software/speech/>

InfoUse, 2560 Ninth St. Ste. 216,

Berkeley, CA 94710; Phone 510-549-6520;

WWW <http://www.infouse.com>

\section{PRODUCTS}

Inspiration Software, Inc

7412 SW Beaverton Hillsdale HWY., Ste. 102,

Portland, OR 97225-2167; Phone 503-297-3004;

WWW <http://www.inspiration.com>

Intellitools, 55 Leveroni Court, Ste. 9,

Novato, CA 94949; Phone 800/899-6687;

WWW <http://www.intellitools.com>

Lernout \& Hauspie, 52 Third Ave.,

Burlington, MA 01803; Phone 781-203-5000;

WWW <http://www.lhs.com>

Microsoft Corporation, One Microsoft Way,

Redmond, WA 98052-6399, Phone 800-426-9400;

WWW <www.microsoft.com>

Seiko Instruments, Consumer Product Division, 2990 Lomita Blvd, Torrance, CA 90505 ,

Phone 877-344-4040;

WWW <http://www.readingpen.com>

TrackStar,

WWW <http://scrtec.org/track/>

INDEX ・ Volume 32

Author Index

Banikowski, Alison K. (October, 1999)

Berghoff, Beth (March, 2000)

Edyburn, Dave L. (May, 2000)

Gagnon, Joseph Calvin (January, 2000)

Korinek, Lori (November, 1999)

Lambie, Rosemary (February, 2000)

Maag, John W. (September, 1999)

Maccini, Paula (January, 2000)

McLaughlin, Virginia L. (November, 1999)

Mehring, Teresa A. (October, 1999)

Reid, Robert (December, 1999)

Reiter, Shunit (April, 2000)

Walther-Thomas, Chriss (November, 1999)

\section{Chronological Index of Titles}

Why They Say No: Foundational Precises and Techniques for Managing Resistance (September, 1999)

Strategies to Enhance Memory Based on Brain-Research (October, 1999)

Collaboration to Support Students' Success (November, 1999)

Attention Deficit Hyperactivity Disorder: Effective Methods for the Classroom (December, 1999)

Best Practices for Teaching Mathematics to Secondary Students with Special Needs (January, 2000)

Working with Families of At-Risk and Special Needs Students: A Systems Change Model (February, 2000)

New Ways of Thinking About Assessment and Curriculum (March, 2000)

Society and Disability: A Model of Support in Special Education and Rehabilitation (April 2000)

Assistive Technology and Students with Mild Disabilities (May, 2000) 